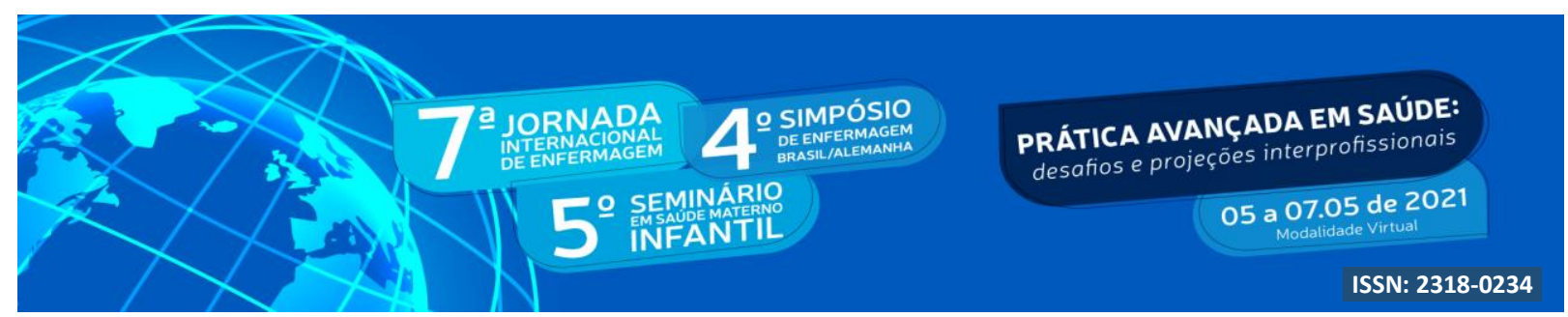

DOI: http://doi.org/10.48195/jie2021-149

\title{
EVIDÊNCIAS CIENTÍFICAS SOBRE TECNOLOGIAS MÓVEIS DE AUXÍLIO À CAPTAÇÃO DE MATERIAIS RECICLÁVEIS ${ }^{1}$
}

\section{Nathália Hoffmann Adames²; Giovana Batistella de Mello ${ }^{3}$; Elviani Santos Stefano ${ }^{4}$; Leandro Medeiros ${ }^{5}$; Kerstin Hämel ${ }^{6}$; Dirce Stein Backes ${ }^{7}$}

\begin{abstract}
RESUMO
Identificar evidências disponíveis na literatura sobre à produção científica relativa às tecnologias móveis de auxílio à captação de materiais recicláveis. Revisão integrativa, de artigos publicados em português, inglês e espanhol, disponíveis na íntegra nas bases de dados LILACS e PubMed. Utilizou-se os descritores "tecnologia", "reciclagem", "resíduos sólidos". Após análise criteriosa das produções previamente selecionadas, nenhum artigo foi incluído por não atenderem o objetivo delineado. $\mathrm{O}$ principal componente explorado pelos artigos incluídos na primeira e segunda rodada de análise estava associado às tecnologias de gerenciamento e não à captação de materiais recicláveis. Optou-se, assim, pela busca livre de produções na Plataforma Google avançada, Android e iOS, mediante os descritores "reciclagem", "aplicativo" e "captação". Localizou-se, então, três tecnologias denominadas: Cataki, Reciclagem de Plásticos e Rota da Reciclagem. Os resultados demostram à necessidade de discutir e fomentar tecnologias móveis de auxílio, também, à captação de materiais recicláveis.
\end{abstract}

Descritores: Aplicativo; Reciclagem; Resíduos sólidos; Tecnologia.

\begin{abstract}
To identify evidence available in the literature on the scientific production related to mobile technologies to aid in the collection of recyclable materials. Integrative review of articles published in Portuguese, English and Spanish, available in full in the LILACS and PubMed databases. The descriptors "technology", "recycling", "solid waste" were used. After careful analysis of the productions previously selected, no article was included because they did not meet the outlined objective. The main component explored by the articles included in the first and second rounds of analysis was associated with management technologies and not with the

\footnotetext{
1 Trabalho de Revisão Integrativa

${ }^{2}$ Estudante do Mestrado Profissional em Saúde Materno Infantil da Universidade Franciscana. E-mail: natiadames@gmai.com

${ }^{3}$ Estudante o curso de Enfermagem da Universidade Franciscana. E-mail: giovanamello20@ outlook.com

${ }^{4}$ Estudante do Mestrado em Ciências da Saúde e da Vida da Universidade Franciscana. E-mail: elvi@yahoo.com.br.

${ }^{5}$ Estudante o curso de Enfermagem da Universidade Franciscana. E-mail: medeirosleandro2018@gmail.com

${ }^{6}$ Doutora em Sociologia. Professora da Universität Bielefeld - Alemanha. E-mail: kerstin.haemel@unibielefeld.de

${ }^{7}$ Doutora em Enfermagem. Professora do Mestrado Profissional em Saúde Materno Infantil e do curso de Enfermagem da UFN e orientadora do trabalho. E-mail: backesdirce@ufn.edu.br
} 


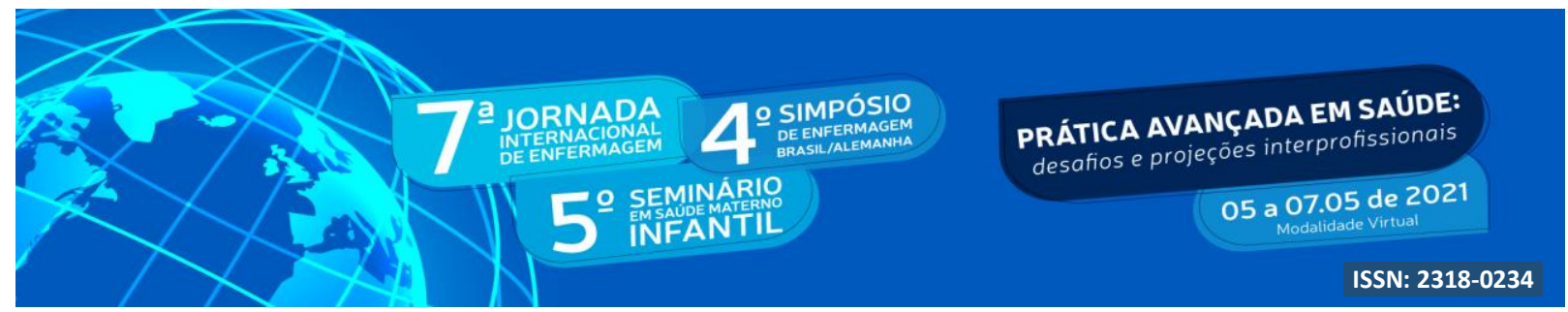

collection of recyclable materials. Thus, we opted for a free search of productions in the advanced Google Platform, Android and iOS, using the descriptors "recycling", "app" and "capture". It was then located three technologies named: Cataki, Plastic Recycling and Recycling Route. The results demonstrate the need to discuss and promote mobile technologies that also help the collection of recyclable materials.

Descriptors: Application; Recycling; Solid Waste; Technology.

\section{INTRODUÇÃO}

No Brasil, atualmente, são coletadas 166 mil toneladas de resíduos sólidos por dia, dos quais são recicladas, anualmente, 608,87 mil toneladas. Verificou-se, a partir de um levantamento, que a composição dos resíduos sólidos urbanos, de acordo com os Planos Estaduais de Resíduos Sólidos é de 50\% material orgânico, 9\% papel/papelão, 13\% plásticos, 3\% vidro, 3\% metais e 22\% rejeitos entre outros (BRASIL, 2019).

A reciclagem associa-se ao processo de realocamento dos bens descartados e/ou dos resíduos de produtos já consumidos, por meio de sua (re)utilização como matéria-prima na produção de novos bens. Refere-se à prática conveniente, que além de minimizar o consumo de recursos ambientais, água, energia e o volume de lixo, visa (re)introduzi-los no ambiente de forma valorativa e sustentável (BRASIL, 2016-2017).

Nessa cadeia produtiva, o catador/colecionador se distingue pela função de reciclar e dar o destino adequado aos materiais descartados pela sociedade e, dessa forma, possibilitar à sua reutilização em novos arranjos produtivos. Além de uma função social e de impacto ambiental, a reciclagem se constitui, para a maioria dos catadores, a principal, se não a única, fonte de renda para o sustento da família (LEAL et al., 2015).

Estima-se, com base no Movimento Nacional dos Catadores de Materiais Recicláveis, que um milhão de pessoas trabalham, no Brasil, na seleção de materiais recicláveis. Embora legalizada desde 2013, a profissão do reciclador se constitui em enorme desafio, tanto no que se refere à coleta, em si, quanto na criação de mecanismos para a conscientização da sociedade. A profissão de catador continua, apesar dos avanços técnico-tecnológicos, um trabalho subjugado e desvalorizado pela sociedade, em geral e, na maioria dos casos, sem o devido apoio dos governos e instâncias políticas locais (BRASIL, 2017, 2019). 


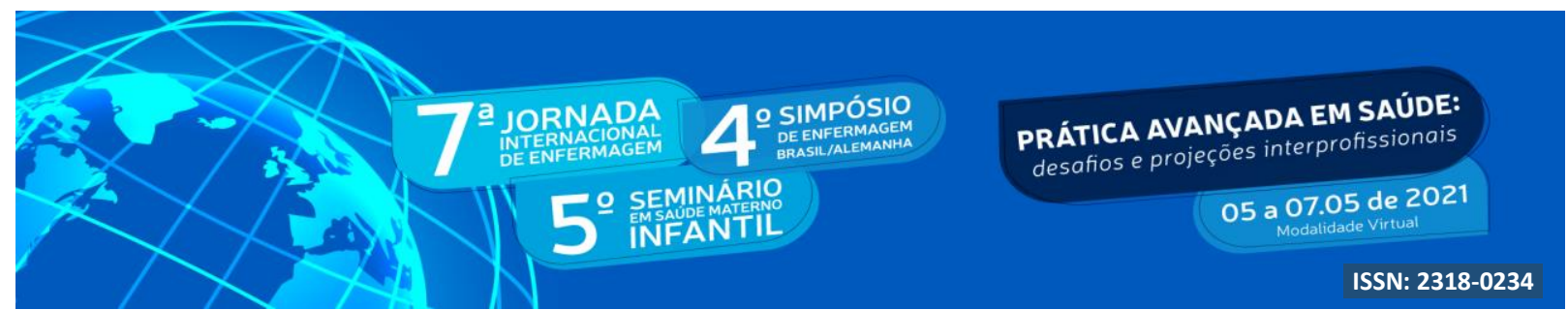

Os recicladores de materiais recicláveis, frequentemente, pertencem a grupos que se encontram em condições de vulnerabilidade social e econômica e, consequentemente, invisíveis aos olhos da sociedade. Entende-se, aqui, por comunidade e/ou individuo em situação de vulnerabilidade social, aquele(a) que está sendo influenciado de forma negativa por fatores ambientais, econômicos e culturais, os quais enfraquecem as suas interações e associações individuais e coletivas (BACKES et al., 2016; 2019).

A profissão de catador/colecionador/reciclador segue, além do que já foi expresso, uma linha de produção amadora ou empírica, isto é, com poucos avanços tecnológicos que possam agregar valor social e econômico à cadeia produtiva. Nessa direção, a tecnologia social representa-se em formato de produto, técnica e/ou metodologia reaplicável, desenvolvida na interação com a comunidade e que representa efetiva solução de transformação social. Trata-se de uma proposta participativa de construção do conhecimento científico e tecnológico, no sentido de favorecer a realização do ser humano e agregar valor ao seu processo de trabalho e, dessa forma, reduzir as desigualdades sociais e promover a inclusão social (SILVA; BOLSON; FERRIGOTI, 2016).

\section{OBJETIVO}

Objetivou-se, com base no exposto, identificar evidências disponíveis na literatura sobre à produção científica relativa às tecnologias sociais móveis de auxílio à captação de materiais recicláveis.

\section{METODOLOGIA}

Trata-se de uma revisão integrativa, que inclui a análise de produções capazes de conferir suporte à tomada de decisão e o fomento de novos processos e tecnologias de intervenção. A revisão integrativa possibilita a síntese do estado do conhecimento de um determinado objetivo de investigação, além de apontar lacunas do conhecimento que precisam ser contempladas em novos estudos. Requer-se, para tanto, padrões de rigor, compreensão e replicação manuseados em estudos primários, para constituir-se em abordagens metodológicas 


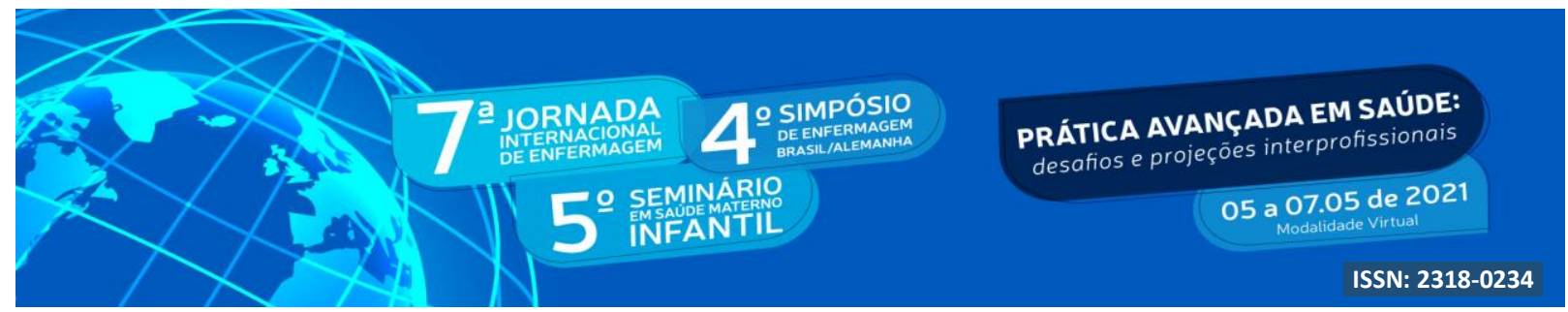

robustas referente às revisões de literatura (NETO et al., 2016; CAETANO; PANOBIANCO; GRANDIM, 2012).

Para a elaboração da revisão integrativa, o pesquisador determina, num primeiro momento, o objetivo do estudo e, a seguir, formula os questionamentos a serem respondidos e/ou as hipóteses a serem testadas. Na sequência, realiza a busca científica em bases de dados, a partir de critérios de inclusão e exclusão previamente estabelecidos. E, por fim, realiza-se a avaliação, a análise crítica, a categorização, a avaliação, a interpretação e a apresentação dos dados em uma estrutura de revisão integrativa (BOTELHO; CUNHA; MACEDO, 2011).

Seguindo-se os pressupostos acima explicitados, o presente estudo foi norteado com base na seguinte questão pesquisa: Quais as evidências científicas relativas às tecnologias sociais móveis de auxílio à captação de materiais recicláveis? De pose desta questão pesquisa, realizou-se consulta aos Descritores em Ciências da Saúde (DeCS), por meio da Biblioteca Virtual em Saúde (BVS), para identificar descritores universais que melhor definissem o objeto sob investigação. Após ampla análise, definiu-se descritores controlados, em português, inglês e espanhol, quais sejam: "Tecnologia/Technology/Tecnología", "Reciclagem/Recycling/Reciclaje" e "Resíduos sólidos/Solid wast/Residuos sólidos".

O levantamento das produções foi realizado entre abril e julho de 2020 e se deu por meio das bases de dados: Literatura Latino-Americana em Ciências de Saúde (LILACS) e no Portal PubMed. Buscou-se, inicialmente, os dados no LILACS, em três etapas de busca avançada, com detalhamento do quantitativo dos artigos e, num segundo momento, no Portal PubMed.

Estabelece-se como critérios de inclusão das produções: artigos publicados na íntegra, disponíveis eletronicamente em português, inglês e espanhol, cujas produções tivessem relação com as tecnologias sociais móveis de auxílio à captação de materiais recicláveis. Foram excluídos os editoriais, cartas ao editor, dissertações, teses, relatos de experiência e estudos reflexivos. Com o objetivo de abranger o maior quantitativo de publicações não foram estabelecidos limites temporais para as produções e publicações.

Na primeira associação de descritores "tecnologia, "reciclagem" e "resíduos sólidos", não foi encontrado nenhum resultado no LILACS. Na segunda associação, por meio dos descritores "tecnologia" e "reciclagem", foram encontrados 14 produções científicas. Já, na 


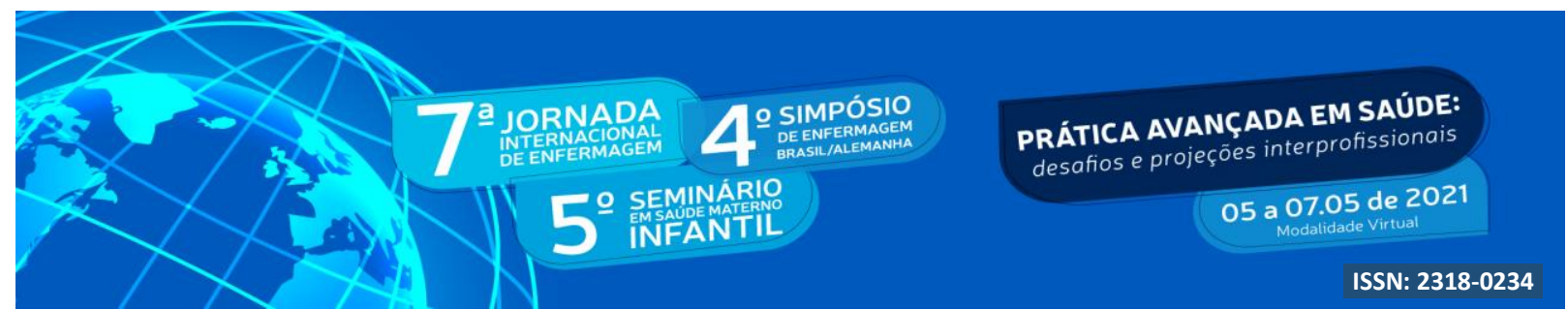

terceira associação, a partir dos descritores "reciclagem" e "resíduos sólidos", foram localizadas 41 produções no LILACS.

A pesquisa no Portal PubMed, à semelhança do que fora realizado no LILACS, resultou em produções mais robustas e em maior número. A primeira associação de descritores "technology", "recycling" e "solid wast" resultou em 448 resultados. A segunda associação com os descritores "technology", "recycling” atingiu-se um número de 5725 produções e, na terceira associação, a partir dos descritores "recycling" e "solid wast", identificou-se 1336 produções.

Após o processo de seleção, identificação e a leitura de todos os títulos e resumos ou abstract das produções encontradas no LILACS e no Portal PubMed e, a partir de uma análise teórica com base nos critérios de inclusão e exclusão previamente estabelecidos, não se obteve nenhuma produção científica para compor o corpus da revisão integrativa. Contudo, decidiu-se pela continuidade do estudo, considerando a sua relevância e pertinência para o avanço da ciência, principalmente, no que se refere ao avanço das tecnologias sociais.

Optou-se, então, pela busca avançada de dados não científicos, na plataforma do Google avançado no período de julho e agosto de 2020, considerando os avanços tecnológicos, em âmbito nacional. Definiu-se como descritores em português, para tanto, "Reciclagem", "Aplicativo" e "Captação".

A pesquisa na plataforma do Google avançado resultou em 236.000 itens. Seguindo-se os pressupostos acima explicitados, a pesquisa na plataforma "Google avançado" foi norteada com base na seguinte questão pesquisa: Quais as produções tecnológicas existentes no mercado relativas às tecnologias sociais móveis de auxílio à captação de materiais recicláveis?

Após o processo de seleção e identificação dos itens/sites e a leitura de todos os títulos e resumos das produções encontradas no Google avançado e, a partir de uma análise teórica com base nos critérios de inclusão e exclusão previamente estabelecidos, excluiu-se desse estudo as tecnologias sociais móveis que não estivessem disponíveis nas plataformas Android e iOS. Obteve-se, por fim, três produções tecnológicas disponíveis no mercado relativas às tecnologias sociais móveis de auxílio à captação de materiais recicláveis para compor o corpus da revisão integrativa, as quais serão apresentadas a seguir.

\section{RESULTADOS E DISCUSSÃO}




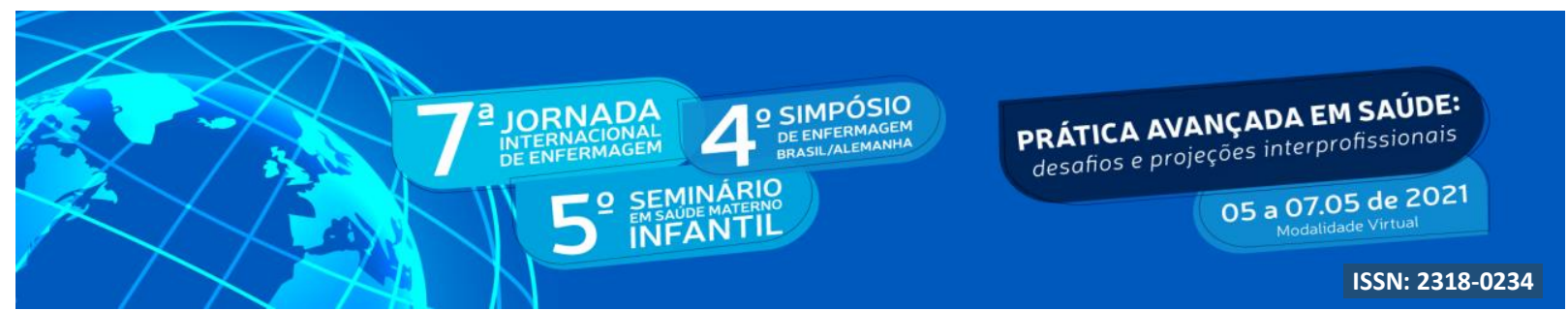

Preencheu-se, após a releitura de cada uma das tecnologias sociais móveis de auxílio à captação de materiais recicláveis, um instrumento com as seguintes informações: nome da tecnologia social móvel, origem e finalidades, as quais são apresentadas em Quadro síntese, a seguir.

Quadro I - Distribuição das tecnologias sociais móveis de auxílio à captação de materiais recicláveis localizadas nas bases de dados Plataforma Google avançado e plataformas Android e iOS.

\begin{tabular}{|c|c|c|}
\hline Tecnologia social & Origem & Finalidade(s) \\
\hline Cataki & $\begin{array}{l}\text { https://play.g } \\
\text { oogle.com/sto } \\
\text { re/apps/detail } \\
\text { s?id=com.ion } \\
\text { icframework. } \\
\text { pimp473818 }\end{array}$ & $\begin{array}{l}\text { - Encontre o catador de materiais recicláveis mais } \\
\text { próximo de você e agende uma coleta pelo } \\
\text { aplicativo. } \\
\text { - Além de catadores, no ecossistema do Cataki você } \\
\text { encontra cooperativas, ferros-velhos, pontos de } \\
\text { entrega voluntária e ecopontos. } \\
\text { - Pode contratar o serviço de remoção de entulho e } \\
\text { resto de podas, remoção de móveis e outros itens } \\
\text { volumosos e pequenos transportes. }\end{array}$ \\
\hline $\begin{array}{l}\text { Reciclagem de } \\
\text { Plásticos }\end{array}$ & $\begin{array}{l}\text { https://apps.a } \\
\text { pple.com/br/a } \\
\text { pp/reciclage } \\
\text { m-de- } \\
\text { pl\%C3\%A1st } \\
\text { icos/id10987 } \\
59058\end{array}$ & $\begin{array}{l}\text { - Localiza pontos de entrega voluntária e } \\
\text { recicladores. } \\
\text { - Filtro por cidade. } \\
\text { - Filtro por tipos de plástico aceitos. } \\
\text { - Avaliação de pontos de entrega voluntária e } \\
\text { recicladores. } \\
\text { - Navegação até o ponto desejado. }\end{array}$ \\
\hline $\begin{array}{c}\text { Rota da } \\
\text { Reciclagem }\end{array}$ & $\begin{array}{l}\text { https://apps.a } \\
\text { pple.com/br/ } \\
\text { app/rota-da- } \\
\text { reciclagem- } \\
\text { tetra- } \\
\text { pak/id48322 } \\
4874\end{array}$ & $\begin{array}{l}\text { - Ação da Tetra Pak a favor da reciclagem e em } \\
\text { defesa do meio ambiente. } \\
\text { - Mostra de forma didática como qualquer pessoa } \\
\text { interessada pode participar do processo de } \\
\text { separação e entrega de embalagens longa vida } \\
\text { para reciclagem. } \\
\text { - Informa onde estão localizadas as cooperativas de } \\
\text { catadores, as empresas comerciais que trabalham } \\
\text { com compra de materiais recicláveis e os pontos } \\
\text { de entrega voluntária que recebem embalagens } \\
\text { Tetra Pak. }\end{array}$ \\
\hline
\end{tabular}

Fonte: Elaboração das autoras

Embora reconhecendo que a inclusão de múltiplos e variados estudos com diferentes delineamentos no processo de amostragem tenha a possibilidade de ampliar o escopo investigativo e enriquecer a pesquisa, no presente estudo não foram localizadas produções científicas que atendessem aos critérios de inclusão previamente estabelecidos. Essa constatação, incialmente frustrante sob o olhar do pesquisador, se constitui, por si só, em um 


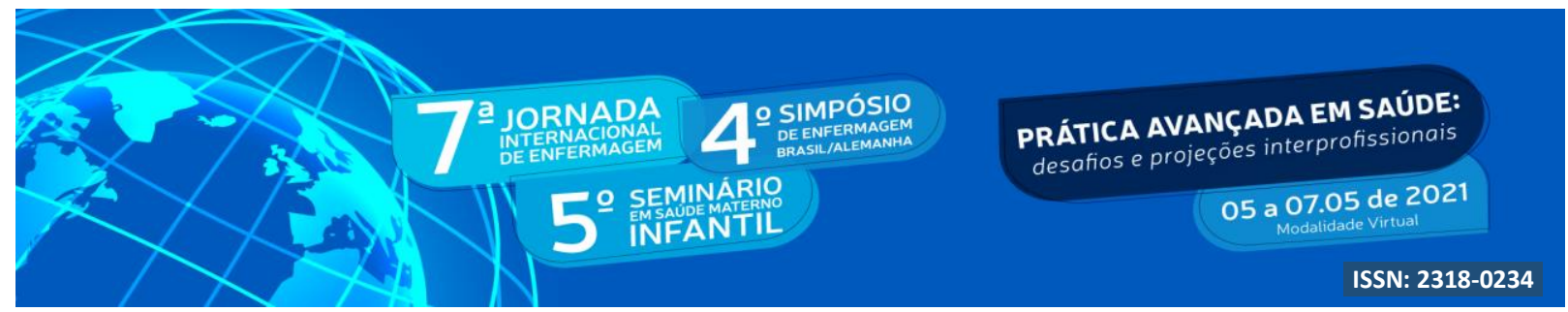

dado relevante, pelo fato de evidenciar importante lacuna na produção do conhecimento científico, na área sob investigação.

Encontrou-se, em todo o processo de busca nas bases de dados, apenas um estudo de caso que descreveu o desenvolvimento de um aplicativo móvel, na configuração de "balanço" de massa e avaliação do ciclo de vida de um sistema de gerenciamento de resíduos. Este, todavia, não foi incluído pelo fato de não se focar às tecnologias de auxílio à captação de materiais recicláveis.

O fato de não ter resultado nenhuma produção científica com aderência à questão pesquisa inicial e, posteriormente com apenas três produções na Plataforma Google, não reduz, portanto, o mérito e a qualidade do presente estudo. Para além dos números, é preciso que se considere os avanços e os retrocessos da ciência, aspectos, frequentemente, negligenciados em produções nas diferentes áreas do conhecimento.

Além deste primeiro ponto de análise, é importante que se considere, também, o descaso da ciência, em geral, às áreas mais vulneráveis da sociedade. Privilegia-se, no âmbito da pesquisa, tecnologias lucrativas e de rápida aquisição pelas empresas comerciais (SILVEIRA; BAZZO, 2009). Mesmo que identificados inúmeros estudos com foco nos tipos de lixo e em tecnologias de apoio ao gerenciamento dos resíduos sólidos, permanece o vácuo e a escassez de possibilidades tecnológicas que assessorem os profissionais colecionadores no que diz respeito à captação de materiais recicláveis.

A tecnologia tem se apresentado como o principal fator de progresso e de desenvolvimento, isto é, tem proporcionado evolução e a revolução nas diferentes áreas do conhecimento. Sob o enfoque econômico, a tecnologia é assumida como um bem social e, associado à ciência, é o meio para agregar valores aos mais diversos produtos e a chave para a competitividade estratégica de um determinado setor. Acompanha-se um crescente investimento no desenvolvimento de inovações tecnológicas na mídia, nos meios acadêmicos, empresariais e outros. Não obstante, a quem mesmo se destinam e servem estas ferramentas tecnológicas?

A tecnologia, portanto, sofre e causa transformações profundas de caráter político, econômico, social e filosófico nos diferentes setores e áreas do conhecimento. Nessa direção, a tecnologia não se reduz ao estudo da técnica ou ao desenvolvimento de uma ferramenta. A 


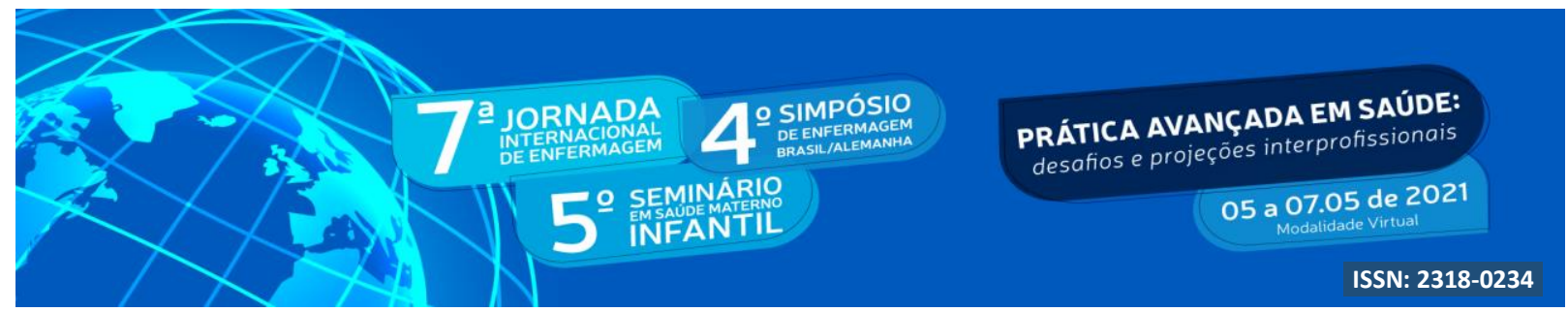

tecnologia envolve saberes e práticas e se associa a um modo de produção e, geralmente, perpetua vinculações sociais no campo das forças produtivas (FREITAS; SEGATTO, 2014).

O avanço da tecnologia e a sua essencialidade, nos dias atuais, é indiscutível. Diversas são, porém, as alternativas tecnológicas, as quais requerem por parte do pesquisador uma escolha criteriosa e ética. A humanidade possui conhecimento, tecnologia, engenhosidade e recursos jamais registrados anteriormente em nossa história, mas para que possam ser acessados e aproveitados por todos, é preciso que se discuta novos conceitos e modelos de desenvolvimento tecnológico (BOCAYUVA, 2009; DAGNINO, 2009).

Admite-se, que a tecnologia móvel e/ou não está inserida amplamente na vida da sociedade, moldando estilos, agregando valor social e econômico, além de provocar alterações e favorecer a dinâmica social como um todo. Não se trata, portanto, em rejeitá-la ou se opor ao seu progresso, o que não passaria de um novo reducionismo. Deseja-se, em suma, que a tecnologia seja utilizada como meio e não como fim, no sentido de favorecer grupos privilegiados. Defende-se o acesso para todos, em especial, para os grupos mais vulneráveis, no sentido de apoiá-los e assessorá-los em processos produtivos mais participativos e dinâmicos.

\section{CONCLUSÃO}

As evidências científicas identificadas, embora não incluídas neste estudo, demostram avanços científicos em áreas vulneráveis como a dos profissionais recicladores de resíduos sólidos, contudo, existe um campo imenso a ser explorado, a partir de novas ferramentas que auxiliem também na captação destes materiais recicláveis.

O principal componente explorado pelos artigos selecionados na primeira e segunda rodada de inclusão está associado às tecnologias de gerenciamento e não às ferramentas de auxílio à captação de materiais recicláveis. Demostram-se, assim, à necessidade de discutir e fomentar tecnologias móveis de auxílio à captação de materiais recicláveis, a fỉm de construir uma sociedade menos desigual e com incentivo para o desenvolvimento de empreendimentos solidários.

Conclui-se, em suma, que existe um descaso da comunidade científica, no que se refere à realização de pesquisas que tragam contribuições meritórias e de impacto científico e 


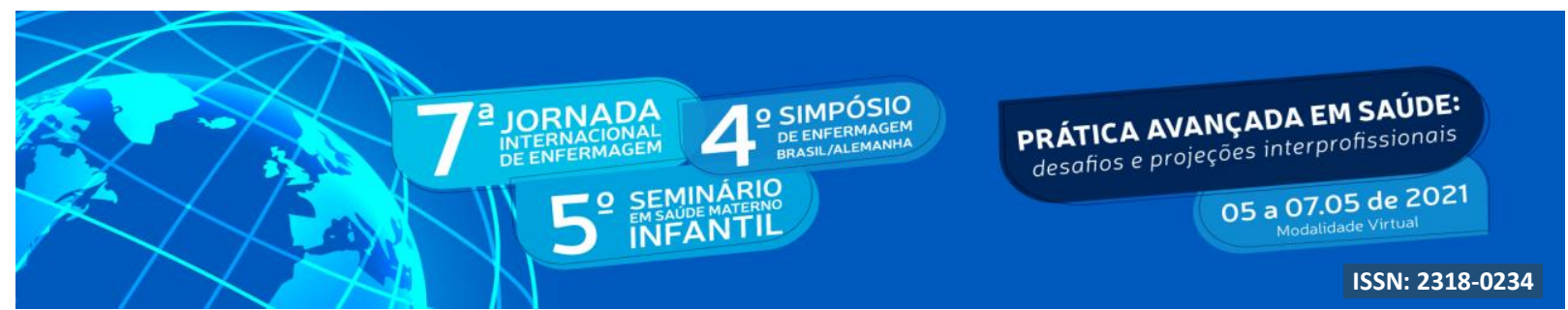

tecnológico para as comunidades e grupos em situações de vulnerabilidade social e econômica. Mesmo que identificados inúmeros estudos com foco nos tipos de lixo e no gerenciamento dos resíduos sólidos, permanece o vácuo e a escassez de possibilidades tecnológicas que assessorem os profissionais colecionadores no que diz respeito às tecnologias sociais móveis de auxílio à captação de materiais recicláveis.

\section{REFERÊNCIAS}

BACKES, Stein Backes et. al. Empreendedorismo social na enfermagem: pensamento conceitual sistêmico. In: Evidências empreendedoras na enfermagem: Ensino, Pesquisa e Extensão. Organizadores: BACKES, D. S., ILHA, S., COLOMÉ, J. S. Santa Maria: Universidade Franciscana - UFN, 2019. 368 p.

BACKES, Stein Backes; ILHA, Silomar; Weissheimer, Amanda Schineider et al. Atividades socialmente empreendedoras na enfermagem: contribuições à saúde/viver saudável. Esc Anna Nery, v. 20, n. 1, pp. 77-82, 2016. Rio Grande do Sul, Brasil. Disponível em: https://www.scielo.br/scielo.php?script=sci_arttext\&pid=S1414-81452016000100077. Acesso em: 16 mai. 2020.

BOTELHO, L. L. R.; CUNHA, C. C. MACEDO, M. O método da revisão integrativa nos estudos organizacionais. Gestão e Sociedade, v. 5, n. 11, p. 121-136, dez. 2011. Disponível em: https://www.gestaoesociedade.org/gestaoesociedade/article/view/1220. Acesso em: 24 abr. 2020. https://doi.org/10.21171/ges.v5i11.1220.

BOCAYUVA, P. C. C. Tecnologia social na transição paradigmática. In: OTERLOO, A. et al. Tecnologias sociais: caminhos para a sustentabilidade. Brasília: s.n., 2009. p. 117-129.

CAETANO, E. A.; PANOBIANCO, M. S.; GRADIM, C. V. C. Análise da produção científica nacional sobre a utilização de grupos na reabilitação de mastectomizadas. Revista Eletrônica de Enfermagem, v. 14, n. 4, p. 965-73, 31 dez. 2012. Disponível em: https://www.revistas.ufg.br/fen/article/view/17112/0. Acesso em: 24 abr. 2020. https://doi.org/10.5216/ree.v14i4.17112.

DAGNINO, R. P. Cinco paradoxos da tecnologia e da política de desenvolvimento. In: OTERLOO, A. et al. Tecnologias sociais: caminhos para a sustentabilidade. Brasília: s.n., 2009. p. 99-116.

FREITAS, Carlos Cesar Garcia; SEGATTO, Andrea Paula. Ciência, tecnologia e sociedade pelo olhar da Tecnologia Social: um estudo a partir da Teoria Crítica da Tecnologia. Cad. EBAPE. BR, Rio de Janeiro, v. 12, n. 2, p. 302-320, jun. 2014 . Disponível em: http://www.scielo.br/scielo.php?script=sci_arttext\&pid=S1679- 

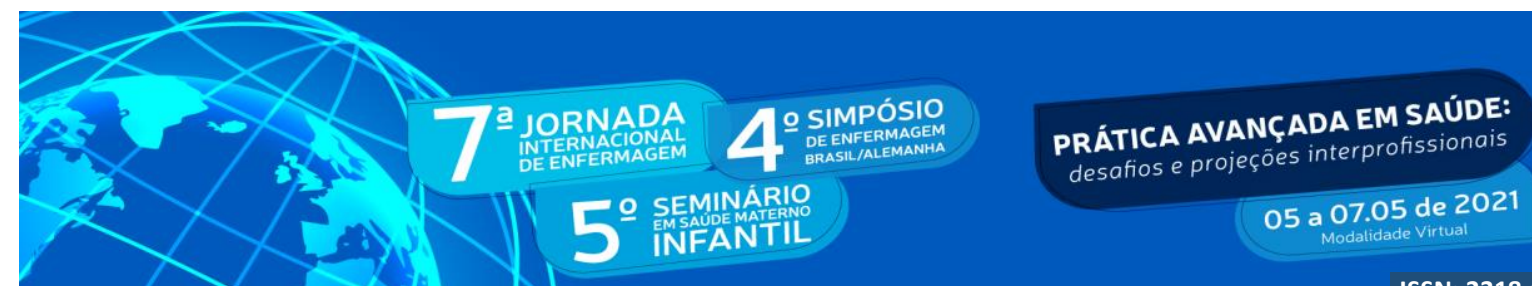

05 a 07.05 de 2021

ISSN: 2318-0234

39512014000200009\&lng=en\&nrm=iso>. Acesso em: 18 mai. 2020. https://doi.org/10.1590/1679-39517420.

GOOGLE PLAY. Cataki. Disponível em: https://play.google.com/store/apps/details?id=com.ionicframework.pimp473818. Acesso em: 13 ago. 2020.

LEAL, A. C.; THOMAZ JÚNIOR, A.; ALVES, Neri et al. A reinserção do lixo na sociedade do capital: uma contribuição ao entendimento do trabalho na catação e na reciclagem. Terra Livre São Paulo, n. 19, p. 177-190, 2015. Disponível em: http://www.agb.org.br/publicacoes/index.php/terralivre/article/view/165/151. Acesso em: 21 mai.2020.

BRASIL. Ministério do Meio Ambiente. Secretaria de Qualidade Ambiental. Programa Lixão Zero: Agenda Nacional de Qualidade Ambiental Urbana. Brasília - DF MMA 2019. Disponível em: https://www.mma.gov.br/images/agenda_ambiental/residuos/programalixaozero_saibamais.p df. Acesso em: 16 mai. 2020.

BRASIL. Ministério do Meio Ambiente. Reciclagem. 2017. Disponível em: https://www.mma.gov.br/informma/item/7656-reciclagem. Acesso em: 16 mai. 2020.

RAMALHO NETO, José Melquiades; MARQUES, Daniela Karina Antão; FERNANDES, Maria das Graças Melo et al. Análise de teorias de enfermagem de Meleis: revisão integrativa. Rev. Bras. Enferm., Brasília, v. 69, n. 1, p. 174-181, fev. 2016. Disponível em: http://www.scielo.br/scielo.php?script=sci_arttext\&pid=S0034-

71672016000100174\&lng=pt\&nrm=iso $>\quad$ Acesso em: $24 \mathrm{abr}$. 2020. https://doi.org/10.1590/0034-7167.2016690123i.

RECICLAGEM DE PLÁSTICOS. Disponível em: https://apps.apple.com/br/app/reciclagemde-p1\%C3\%A1sticos/id1098759058. Acesso em: 13 ago. 2020.

ROTA DA RECICLAGEM. Disponível em: https://apps.apple.com/br/app/rota-da-reciclagemtetra-pak/id483224874. Acesso em: 13 ago. 2020.

SILVA, C. L.; BOLSON, C. R.; FERRIGOTI, C. M. S. Tecnologia e inclusão social: Cooperativa Catamare. Interações, Campo Grande, v. 17, n. 3, p. 516-527, jul./set. 2016. http://dx.doi.org/10.20435/1984-042X.

SILVEIRA, Rosemari Monteiro Castilho Foggiatto; BAZZO, Walter. Ciência, tecnologia e suas relações sociais: a percepção de geradores de tecnologia e suas implicações na educação tecnológica. Ciênc. Educ. Bauru, v. 15, n. 3, p. 681-694, 2009. Disponível em: http://www.scielo.br/scielo.php?script=sci_arttext\&pid=S1516-

73132009000300014\&lng=en\&nrm=iso>. Acesso em: 18 mai. 2020. https://doi.org/10.1590/S1516-73132009000300014. 